\title{
Planning a university as an instrument of change
}

\author{
A. M. Ahmad \\ Faculty of Architecture, University of Khartoum, Sudan
}

\begin{abstract}
In July 2011 a new African state was born, The Republic of South Sudan, after the region voted for separation from The Sudan. It has a rich diversity of natural resources and subcultures but, crippled by neglect and intermittent civil wars for half a century, remains poor in human resources and practically all physical (infra- and super-structural) aspects. Beyond the local vernacular, South Sudan has neither a tradition in physical planning nor one in urban architectural design. Architectural education started in the Sudan in 1957. Today there are 16 schools of architecture in the North and one in the South. A university now being planned in the town of Awiel in the new state faces many challenges since it is made to play several roles besides the normal educational ones. Our vision while setting up the university is to create an urbanising force in a rural or semi-urban region generating employment, changing lifestyles and raising aspirations. The university would attempt to introduce trends in urban planning and architectural design responsive to climate and culture. It would utilise renewable energy sources (which here is a necessity not a curiosity) and set an example in environmental protection and enrichment to be followed hopefully by other institutions. The project would also include dealing with seasonal sheet floods and harvesting water, utilising alternative building technologies for ancillary parts of the campus and treating and recycling sewage. In short, our objective is to apply relevant, affordable principles of eco-neighbourhood and healthy town design. Now that the project is at the conceptual planning stage, this paper hopes to generate some fruitful debate and get some expert advice to help our vision to materialise.
\end{abstract}

Keywords: South Sudan, university campus planning, planning for change, eco-design. 


\section{Introduction}

As required by the 2005 Comprehensive Peace Agreement [1], signed between the Government of the Sudan and the South Sudanese Liberation Movement, a referendum was conducted to allow the southerners to vote for either remaining in a united Sudan or separating and creating their own independent state. On 9 July 2011, they had voted almost unanimously for the latter choice and the Republic of South Sudan was born. It lies between latitudes 3 and $13 \mathrm{~N}$ and longitudes 24 and $36 \mathrm{E}$ and covers an area of 619,745 square kilometres. It is landlocked and bordered by six countries with an estimated population of 10 million [fig 1]. A purely African country, it is unlike the Sudan which officially is Arab but has a mixed Arab/African population of about 30 million (2008). It is rich in natural resources - fresh water, arable land, timber and petrol among others - as well as animal resources - cattle, sheep and a diversity of wildlife. Yet it is poor in human resources with high rates of illiteracy, unemployment, endemic diseases, infant mortality, a short life expectancy at birth and superstitious thinking [2]. The population is animist and Christian with a small minority of Muslims. Cattle herding and pastoralism are widespread. Due to the civil war between the Arabised North and the African South running through most of the half century 1955-2005, it remains poor also in all infra- and superstructures and services. A lot of its settlements have been badly affected by the war and until recently, some were semi abandoned.

\section{Setting up a new university}

A new university is to be set up in South Sudan, the University of Northern Bahr El-Ghazal (UNBEG). It will be located in Awiel, capital of Northern Bahr ElGhazal Province lying about 800 kilometres north-west of Juba, the national capital. Awiel lies at latitude $8 \quad 46^{\prime} \mathrm{N}$, longitude $2724^{\prime} \mathrm{E}$ and at an altitude of $425 \mathrm{~m}$ above mean sea level. The town evolved an irregular form growing as the physical features permitted but with a rectangular grid imposed on its planned neighbourhoods. With a population of about 10,000 (in 2009), it consists almost entirely of single storey buildings, with some public buildings like an airport, a railway station, a general hospital, a Roman Catholic church and a football stadium. The site reserved for the university is an irregular quadrangle roughly 1000 by $800 \mathrm{~m}$ lying on the western part of the town and linked to it by an asphalt road. A provincial road from Wau passes west of the town.

UNBEG would start with four faculties: Preparatory, Community and Vocational Studies; Petroleum Engineering, Mining and Energy Studies; Architecture and Physical Planning and, finally, Public Health, Nursing and Midwifery [3]. Assuming an initial average of 40 students per class, we can aim at a target population of 800 students; the institution would thus comprise about 900 people in total by the end of the first five years. 


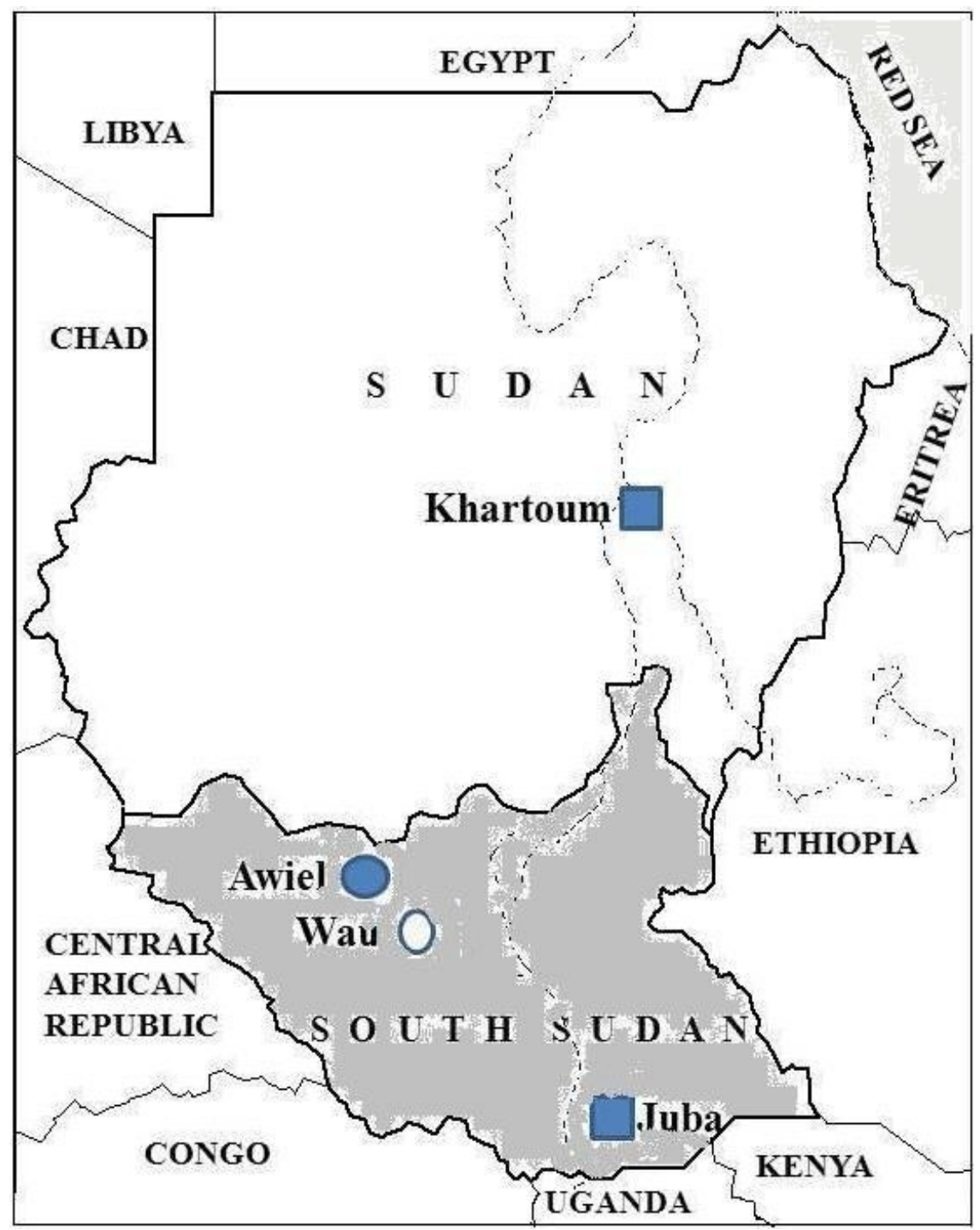

Figure 1: $\quad$ South Sudan and its neighbours.

\section{Analysis of the physical environment}

Due also to the civil war, only a few meteorological stations in the south have continued to operate. No up to date climatological normals for Awiel exist but those for Wau, the capital of Bahr El-Ghazal State, can be adopted since for physical planning and architectural design purposes a distance of 150 kilometres 
between two towns within the same climatic zone can hardly affect the readings' validity. These cover the normal 30-year period - in this case 1981-2010 [4].

They show a composite climate more on the warm humid side (table 1). Throughout the year variations in air temperature are small with mean maxima ranging from 31.9 to $38.7^{\circ} \mathrm{C}$ and mean minima from 18.9 to $23.7^{\circ} \mathrm{C}$; seasonal and diurnal ranges of temperature are relatively small.

Table 1: $\quad$ Climatological normals (1981-2010) for Wau.

\begin{tabular}{|c|c|c|c|c|c|c|c|c|c|c|c|c|c|c|}
\hline & & $\mathrm{J}$ & $\bar{F}$ & II & $A$ & II & J & $J$ & $A$ & S & 0 & $\pi$ & D & Y \\
\hline \multirow{2}{*}{$\begin{array}{l}\text { Sir Temp } \\
\text { (C) }\end{array}$} & daily max & 35.7 & 37.4 & 38.7 & 387.9 & 35.5 & 33,3 & 32,0 & 31.9 & 33.0 & 34,6 & 35.6 & 35.6 & 35.1 \\
\hline & daily min & 18.9 & 20.2 & 21.0 & 23.7 & 23.2 & 21.3 & 21.2 & 21.1 & 21.3 & 21.7 & 20.7 & 19,3 & 21.3 \\
\hline \multirow{2}{*}{$\begin{array}{l}\text { Sunshine } \\
\text { Duration }\end{array}$} & bras & 8.1 & 7.3 & 6.4 & 6.4 & 6.3 & 6.0 & 5.4 & 5.9 & 6.3 & 6.9 & 7.9 & 8.3 & 6.8 \\
\hline & $\%$ & 70 & $6 ?$ & 54 & 33 & 51 & 50 & 44 & 47 & 53 & 58 & 67 & 71 & 57 \\
\hline R. Hu & $\%$ & 26 & 24 & 31 & 44 & 58 & 67 & $7 !$ & 73 & 98 & 64 & 46 & 31 & 30 \\
\hline Rainfall & $\mathrm{mm}$ & 0.6 & 0.3 & 12.2 & 57.3 & 113.2 & 163 & 196 & 201.2 & 171.9 & 101 & 16.5 & 0.3 & 1035 \\
\hline \multirow{2}{*}{$\begin{array}{l}\text { Prevailing } \\
\text { IVinds }\end{array}$} & direction & 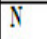 & 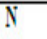 & $\pi$ & SIT & SIT & STI & STI & STI & STI & $5 \pi$ & $\bar{N}$ & 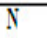 & \\
\hline & speed km h & 6 & 7 & 7 & 7 & 6 & 6 & 6 & 6 & 5 & 4 & 5 & 6 & \\
\hline
\end{tabular}

A seven-month rainy season starts in April and lasts till October; the period December to February is practically dry. The total annual rainfall is $1035 \mathrm{~mm}$ with the highest monthly amount, $202.2 \mathrm{~mm}$, falling in August. During these seven months the prevailing winds blow from the south-west, mostly at about $6 \mathrm{~km} / \mathrm{hr}$; during the remaining five months they blow from the (drier) north at slightly higher speeds. Thus, mean relative humidities are highest in July (72\%) and August (73\%) and lowest in January (26\%) and February (24\%). Bright sunshine duration is at its highest in December ( $8.3 \mathrm{hrs})$ and January ( $8.2 \mathrm{hrs})$ and its lowest in July (5.4 hrs). Awiel, north of Wau, is slightly hotter and drier.

A special feature of this region is the seasonal sheet flooding; it occurs for 2 3 months during the rainy season. At its peak all but the paved streets is flooded, the place being a plain crossed by some watercourses with a mild slope northwards.

\section{Architectural education in the Sudans}

Architectural education started in the Sudan in 1957 in the University of Khartoum, the only full time university then [5]. By 2011 there were 16 departments of architecture in the Sudan; after secession, there was only one university in the South teaching architecture.

All specialisations are badly needed at present in the Republic of South Sudan. Architecture and physical planning are no exception. As more southerners move from the North to the long-neglected South, they face a pressing need for housing, rehabilitating settlements and planning and constructing new neighbourhoods. At a different level, there is a need to 
formulate a distinct South Sudanese character in both architecture and town planning - distinct, that is, from that of the northern Arab Muslim neighbour and going hand in hand with the new national consciousness.

The new state inherited nine public universities, only five of which are now working, and 15 private ones. Architecture is taught in only one, the University of Juba. These universities, when part of old Sudan, suffered for more than two decades from controversial policies of the so-called 'Higher Education Revolution' through grossly inflated intake of students, watering down admission requirements, arabicisation, Islamicisation of knowledge and adopting political affiliation as a criterion for appointments, promotions, assignment of duties or abrupt ending of services [6]. Higher Education in the South is now struggling to recover [7].

\section{Planning the new university}

The University of Northern Bahr El-Ghazal aims ultimately to serve the core functions of any university: teaching, scientific research, serving the community and innovation. It would possess the buildings and outdoor spaces appropriate for the task (in common with some, not all, universities in the Sudans). This is seen as a normal planning and design challenge - normal in the sense that it demands little more than what the majority of consultancy offices routinely offer.

However, in this project, we, as a team entrusted with preparing a master plan for the university, are looking at UNBEG in a different light - as an institution which, apart from what is being taught within its walls, strives to be an instrument of change. What we hope would distinguish UNBEG from other Sudanese universities would lie in the different ways of handling its planning, servicing and the design and construction of its individual buildings and outdoor spaces. Our vision is to create a dynamo and a landmark in the new-born state an urbanising force in a semi-urban area generating employment, demonstrating appropriate design, construction and servicing technologies, and curbing inequalities. By 'urbanising' here we mean modifying lifestyles and adopting urban ones rather than merely activating movement into urban areas. Thus in implementing our vision the Faculty of Public Health, Nursing and Midwifery and that of Community and Vocational Studies would be just as instrumental as the Architecture and Physical Planning Faculty. The universally accepted Millennium Development Goals (MDGs) are one suitable guide for our work [8] especially in the fields of environmental sustainability, poverty reduction and improving health standards.

\subsection{Planning considerations}

Phase I of the master plan (for the next 15 years) is seen to include the four faculties, the administration, a library, a refectory, student hostels, a club, a theatre and different sports fields. The implementation would proceed in regular phases as funding becomes available. 
In the planning field we are faced with four main challenges. The first is allocating land uses to fulfil the normal functions of the institution; this covers the academic, social, cultural, sports and recreational activities. It includes also facilitating future growth of the university and the ease of expanding each faculty. The site, 80 hectares, is large by the standard of a provincial university and can support different extra-mural activities to vitalise both university and town life.

The second challenge is responding to the physical environmental factors including the mostly warm humid climate, the topography and other physical features (e.g. a neighbouring wood) and the utilisation of local materials.

Closely related to this, the third challenge is dealing with seasonal floods and harvesting water. This is done for the benefit of the university and for the regional community at large. It involves protecting the site through raising the ground floor level of buildings safely above flooding level and building embankments and boundary walls. At the regional level it involves also elaborate digging of hafirs to collect and store water for human, livestock and wildlife use in the dry season.

The fourth main challenge is that of applying relevant, affordable principles of eco-neighbourhood and healthy town planning [9]. This includes collection and disposal of solid waste, collection, treatment and recycling of sewage, isolation and safe disposal of medical waste, creation of green belts and utilisation of the unused part of the site for agricultural and other activities. The university will have to generate its own electricity supply, or at best, supplement its share from the national grid, from unit generators as well as from solar and wind sources. The sewage treatment plant in particular demands special design so as not to turn into a health hazard during the flood season. The university should guide Awiel ultimately to grow as a 'healthy town', target selfsufficiency and reduce its ecological footprint.

\subsection{Architectural design considerations}

The primary challenge in the architecture field i.e. in the design of individual buildings and outdoor spaces is fulfilling functional requirements relating to all spaces within the university (lecture rooms, laboratories, library, offices, hostels, playing fields, etc). Responding to climatic elements through appropriate built form, construction, orientation, shading, ventilation, lighting, protection from driving rains, etc, is the twin challenge.

Secondary buildings in the compound, such as hostels, the refectory and club, should cost less per square metre than main buildings. They thus offer an opportunity to use intermediate and appropriate technologies: stabilised mud, pressed blocks, rammed earth constructions and improved thatch roofing. That would be also an opportunity to involve the youth in construction and planting and provide a demonstration of materials and methods making the campus site an open workshop and exhibition for the community.

Of equal importance is the search for an identity for South Sudanese architecture setting it apart from North Sudanese architecture and even from other sub-Saharan African architecture. This comes from a closer study of the 
vernacular. Not that the university should be designed as a residential neighbourhood but that it should harmonise with it and echo and upgrade some of its elements. Harmony in the built environment will be sought through some unifying factors: style, scale, materials, colour (South Sudanese are much more responsive to colour than Northern Arabs), etc. These should not only guide the aesthetics of the first building designs but also all future developments. Still, following the principle of 'unity in diversity' each building should have its own character emanating from its nature and the activities it houses.

\section{Interaction with the local community}

The planning, furthermore, should consolidate the institution's role in serving the local community. This could come at various levels. It should facilitate sharing sports facilities, a public library, an art gallery or theatre which is a relatively simple task. Raising the awareness of women and youth to vital issues, training them in some handicrafts or other income-generating activities is a further stage. Then come the harder tasks of attempting to influence and upgrade the prevalent pastoralist way of life and gradually introduce more characteristics of urban lifestyles.

\section{The master plan concept}

The site lies at the western end of a main street coming from the town centre in a roughly west/south/west direction and terminating in another street running at right angles to it. An irregular quadrangle measuring roughly 1000 by 800 metres, the site lies in a vast open space bordered by main streets on two sides and scattered informal dwellings on the other two (fig 2), the longer dimension running east-west. The street leading from the town centre provides the master plan with a strong natural axis and suggests the location of a conspicuous entrance to the university, about 185 metres from its northern corner. This front side of the campus would be recessed from the street line to create a green strip for environmental purposes, extension of activities and the inevitable future need to widen the street.

One basic concept in laying out the campus is to allow freedom of planning. A full university campus takes decades to mature and cannot realistically be designed from the start. As time passes, especially in a nascent state, conditions and requirements change and old designs are regularly superseded. Thus, after the first phase or phases, directions of growth are suggested but the planning has to be left to the coming generations. The form, location and orientation of the site suggest its zoning into three strips running along its east-west axis - the central one would be the teaching zone; the northern strip would house the residential, sports and entertainment activities and be partly accessible to the outside community, this is where interaction with the community happens; the southern strip is dedicated to extra-mural activities and investment. 


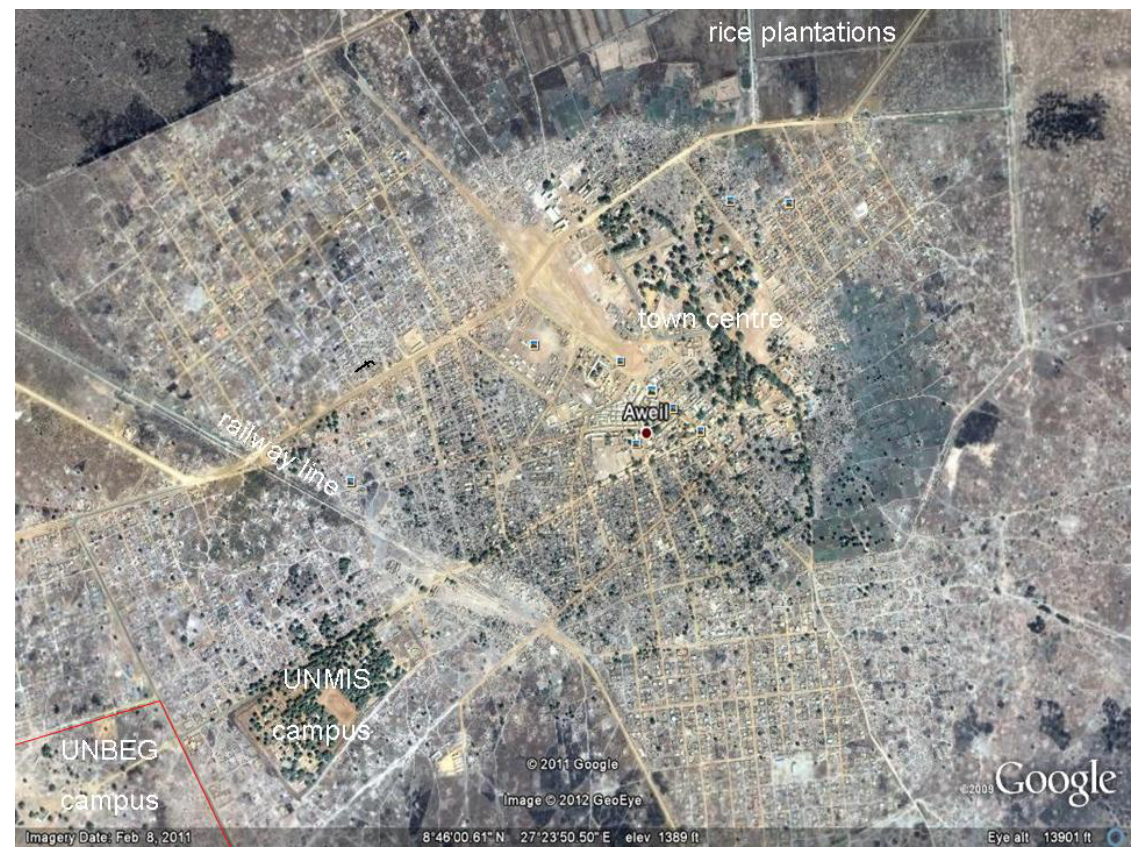

Figure 2: $\quad$ An aerial photo of Awiel.

In this phase of planning the campus we propose three complexes: a teaching/ administration, a residential and a sports/recreational complex in addition to power generating and sewage treatment plants. The main entrance leads to a forecourt and the administration building and beyond it to the four faculties and the library. This axis also suggests the westward direction of growth of the teaching/administration complex. The northern part of the site would accommodate the students' hostels and refectory linked to the teaching/administration complex by a roughly north south spine but separated by a broad route starting at the students' entrance. West of the residential complex would lie the sports fields and the theatre. Their location is guided by three considerations: proximity to the hostels, separation from the teaching complex and the need to provide an entrance for the outside community to attend and participate in university activities. This would be in the northern boundary wall.

Round structures are dominant in the traditional settlement patterns of South Sudan. The basic shelter unit is the hut composed of a mud wall structure usually cylindrical, sometimes oblong and a conical thatched roof with generous overhangs. The roof rises in layers which gives it an accentuated, dignified presence (fig 4). A typical traditional compound is composed of a cluster of huts of various sizes and forms surrounding a circular open yard (fig 3). This is taken to inspire our planning. Urban cubic forms of brick, stone and concrete spread over the town but we are getting our inspiration from the vernacular. Low-rise buildings, not exceeding three floors in height, are seen as the most appropriate. Cattle have a special significance in South Sudanese culture; they are part of 


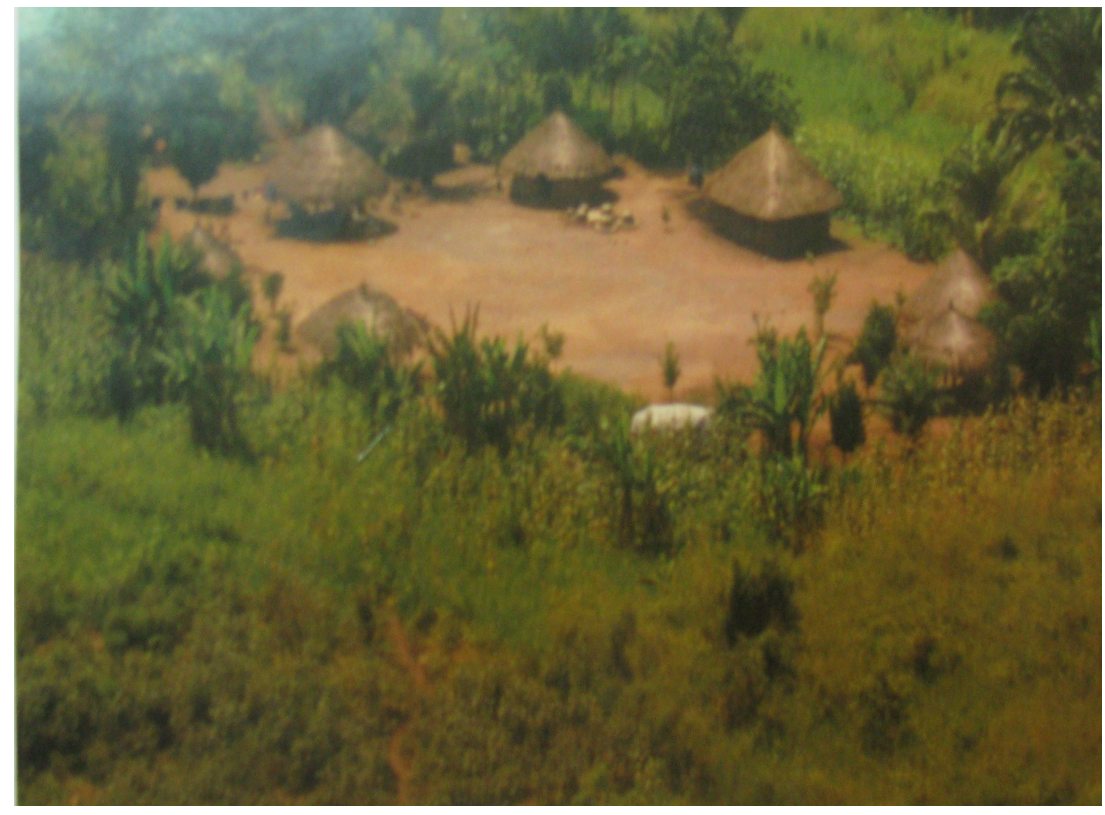

Figure 3: The start of a residential compound showing a circular open space surrounded by dwellings.

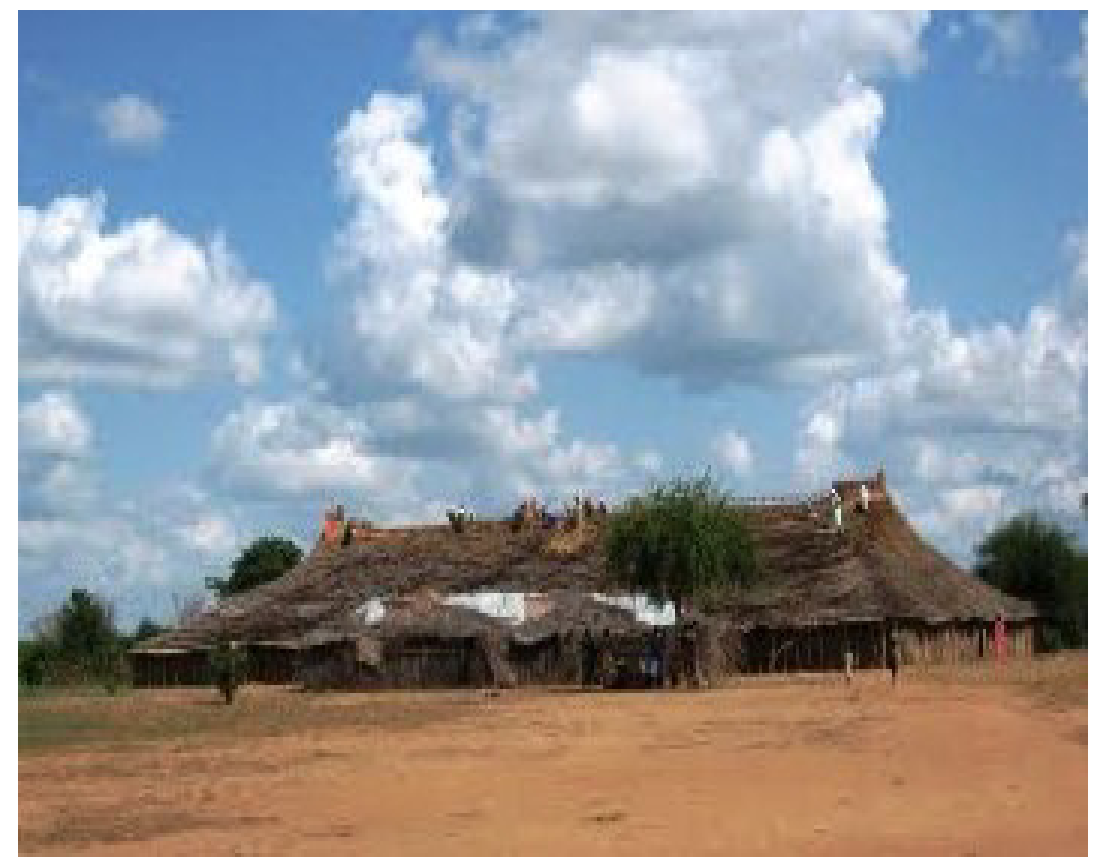

Figure 4: The vernacular of South Sudan. 
their consciousness having acquired a symbolic value that transcends their material one. (Could cattle horns, for example, inspire architectural form much as they did to some of Le Corbusier's Indian forms?). The planning adopts curvilinear patterns, plastic forms, dominant roofs and central courts seen as familiar features to the people.

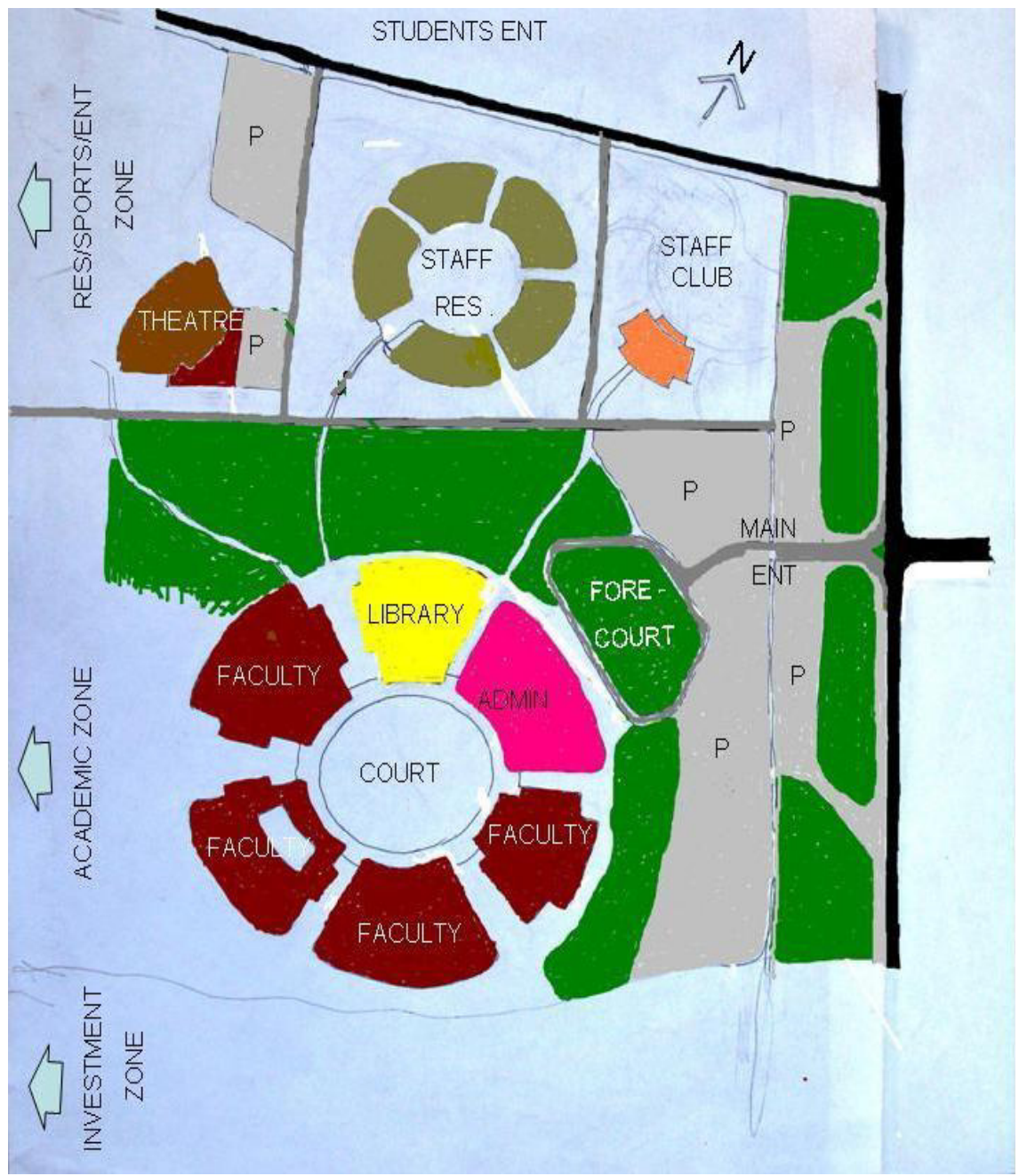

Figure 5: $\quad$ Proposal for phase I of UNBEG campus. 


\section{In conclusion}

We are at present at an early conceptual stage of planning awaiting deeper study results and seeking expert advice on technical issues: solar energy utilisation, aero-generation, sewage treatment and recycling, flood risk planning, passive environmental controls, intermediate construction technologies, etc, while at the same time searching for authentic character in planning and design.

We are attempting to take Sudanese university design a step forward by implementing feasible research outputs, guided by Millennium Development Goals and other local initiatives, all handled within a strong regional frame.

To be effective, UNBEG has to set itself as part of a network of universities, national and foreign, collaborating to achieve specified aims. While appearing highly ambitious, these tasks are not unrealistic and can be achieved in the 15year period indicated in the university prospective programme provided the political will and some international and regional assistance and collaboration are on our side.

\section{References}

[1] Republic of the Sudan. Comprehensive Peace Agreement. 2005.

[2] Republic of the Sudan. Ministry of Interior Affairs. Depatment of Staiatics. 2008 Population census. Khatoum, 2009.

[3] University of Northern Bahr El-Ghazal. UNBEG Prospectus 2011. Khartoum 2011.

[4] Republic of the Sudan. Sudan Meteorological Authority. Climatological normals 1981-2010.

[5] Cairo University, Khartoum Branch, the only other university in the country, worked on a part-time basis and was closed in 1990.

[6] Republic of South Sudan. Academics and Researchers Forum for Development (ARFD) and Ministry of Higher Education, Research, Science and Technology. Proceedings of Conference on the future of higher education in South Sudan. Juba 14-15 November 2011.

[7] Sudanese Academics Association. Proceedings of Symposium on 'The present state and future of higher education in the Sudan'. Ein Shams University. Cairo. 1-5 August 1998.

[8] United Nations Development Programme (UNDP). Millennium Development Goals. 2005.

[9] See, for example, Environment and Urbanization issue Vo 11 Nol April 1999, dedicated to 'healthy cities, neighbourhoods and houses'. International Institute for Environment and Development. London. 